\title{
El misticismo en Ortega y Gasset
}

\author{
Ignacio SÁnchez CÁmara
}

Universidad Rey Juan Carlos de Madrid ignacio.sanchez@urjc.es

DOI: https://doi.org/10.15366/bp.2020.24.001

Bajo Palabra. II Época. No 24. Pgs: 21-36

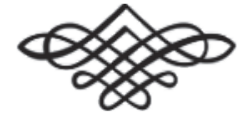


Recibido: 06/11/2019

Aprobado: 28/07/2020

\section{Resumen}

El misticismo puede ser entendido como el objeto de la obra de los místicos que conduce a la unión espiritual con Dios y como lo relativo a "lo místico", a lo trascendente, a lo que no pertenece al mundo. Este es el sentido que aparece en la obra de Wittgenstein. En este artículo se trata de analizar la actitud de Ortega y Gasset hacia los dos aspectos. La conclusión es que su obra es compatible con la afirmación de lo trascendente y, en definitiva, con el cristianismo.

Palabras clave: Ortega y Gasset, misticismo, trascendencia, Dios, realidad radical, vida humana, ser fundamental, sentido, Absoluto.

\section{Abstract}

Mysticism can be understood as the object of the mystics' work that leads to spiritual union with God and as relative to "the mystical", to the transcendent, to what does not belong to the world. This is the sense that appears in Wittgenstein's work. This article tries to analyze the attitude of Ortega y Gasset towards both aspects. The conclusion is that his work is compatible with the affirmation of the transcendent and, ultimately, with Christianity.

Keywords: Ortega y Gasset, mysticism, transcendence, God, radical reality, human life, fundamental being, meaning, Absolute. 
$\mathrm{E}$ 1 misticismo se refiere al estado de la persona que se dedica con especial intensidad a Dios y a la vida del espíritu. La mística consiste en la descripción del itinerario espiritual que conduce a la unión entre el alma y Dios, en la comunicación inmediata y directa entre ambos. La mística viene a ser experiencia de lo divino. William James caracterizó la experiencia mística por cuatro notas: inefabilidad, cualidad de conocimiento, transitoriedad y pasividad. El místico afirma la dificultad o imposibilidad de expresar su experiencia mediante el lenguaje; le parece que sus estados afectivos son también estados de conocimiento; no pueden mantenerse durante mucho tiempo; y siente como si su voluntad estuviera sometida a una fuerza superior ${ }^{1}$. El misticismo no se opone a la racionalidad ni es incompatible con la filosofía. Por el contrario, la filosofía, en sus orígenes presocráticos y en el platonismo, puede entenderse como un intento de armonización entre el racionalismo y el misticismo ${ }^{2}$. El objeto de este trabajo no es sólo la Mística como disciplina ni, por tanto, sólo la obra de los místicos. Entenderemos aquí bajo el término "misticismo", también "lo místico" en el sentido que da Wittgenstein a esta expresión, es decir, lo que está más allá de los límites del mundo y de mi vida, esto es, de mi yo y mi circunstancia (Ortega y Gasset). Místico es, en este sentido, lo trascendente al mundo, lo que está más allá de él, lo que no le pertenece ${ }^{3}$.

El misticismo es conciencia de la presencia de Dios. El místico entiende como algo natural "la presencia de Dios" ${ }^{4}$. Ortega anuncia el advenimiento de un nuevo místico que "habla poco de Dios, sólo de los estados espirituales y aun corporales de sí mismo mientras se ocupa con Dios" ${ }^{5}$. Pero, en ocasiones, resulta que para Ortega el misticismo parece rebasar el ámbito de lo puramente religioso. Cuando Parménides nos cuenta sus averiguaciones añade que tenían para él un valor místico. Piensa Ortega que los descubrimientos científicos también tienen carácter místico ${ }^{6}$.

\footnotetext{
1 James, W., Las variedades de la experiencia religiosa, trad. de F. J. Ivars, Barcelona, Península, 1986, pp. 286 s.

2 Jaeger,W., The theology of the Early Greek Philosophers, Oxford University Press, 1947.

3 "No cómo sea el mundo es lo místico sino que sea. La visión del mundo sub specie aeterni es su visión como-todo-limitado. El sentimiento del mundo como todo limitado es lo místico" (Wittgenstein, L., Tractatus logico-philosophicus, traducción de Muñoz, J. y Reguera, I., Madrid, Alianza, 1973, 6.44, 6.45, p. 181.

${ }^{4}$ Ortega y Gasset, J. Historia como sistema, Obras Completas, VI, Madrid, Taurus, 2006, p. 51.

5 Ortega y Gasset, J., En torno a Galileo, O.C., VI, p. 492.

6 "Todo descubrimiento "científico", esto es, toda verdad nos pone de repente en una visión inmediata de un mundo que hasta entonces desconocíamos y con el cual, por lo mismo, no contábamos. De pronto, como si se corriese un velo se nos hace maravillosamente manifiesto -somos “visionarios"-; más aún, nos parece que hemos
} 
Y, a continuación, comenta el caso de Descartes y su descubrimiento místico del nuevo método. Pero eso no impide reconocer que ciencia y mística son dos cosas distintas ${ }^{7}$.

Con apariencia paradójica, Ortega identifica el realismo artístico con el misticismo. "El realismo artístico nuestro y el misticismo de los éxtasis parecen apariciones contradictorias y son una misma cosa: inmediatez a las cosas" ${ }^{\text {. }}$.

Por otra parte, toda mística es un intelectualismo ${ }^{9}$. En contra del cientificismo, Ortega reivindica el arte y la mística, y también la idea de que el arte y la mística, que es un arte metafísico, tiene un lugar junto a la ciencia ${ }^{10}$.

Ortega distingue también entre la filosofía y la mística. Los místicos nos ofrecen un viaje maravilloso y, además, nos seducen con su lenguaje. "Los místicos han solido ser los más formidables técnicos de la palabra, los más exactos escritores. Es curioso y -como veremos- paradójico que en todos los lenguajes del mundo los clásicos del idioma, del verbo hayan sido los místicos" ${ }^{11}$. Además han tenido siempre un gran talento dramático ${ }^{12}$. El camino siempre está dividido en etapas, pero al llegar a la última nos abandona en medio de una decepción. De vuelta del éxtasis, el místico se vuelve taciturno porque lo que allí ha contemplado resulta inefable. "El místico de su travesía ultramundana no trae nada o apenas qué contar. El clásico del lenguaje se hace especialista del silencio" ${ }^{13}$. Pero eso no significa un desdén o desprecio hacia el saber místico. El libro místico es un itinerario de la mente hacia lo Absoluto ${ }^{14}$.

También sería un error desdeñar lo que ve el místico porque sólo pueda verlo él. La objeción deriva principalmente de que de la visión mística no redunda ningún beneficio alguno intelectual. Eso no impide que algunos, como Plotino, Eckehart y

sido arrebatados de nuestro mundo habitual, "burgués” y nada místico a otro, por un poder extraño -caemos en éxtasis o "transporte". Es indiferente cuáles sean nuestras convicciones previas sobre lo real y lo divino, lo vulgar y lo mágico: la situación, la experiencia mística se reproducirá siempre con análogos caracteres” (Ortega y Gasset., J., "Fragmentos de Origen de la filosofía", O.C., VI, p. 851).

7 Ortega y Gasset, J., Sistema de la Psicología, Lección III, O.C., VII, p. 458.

8 Ortega y Gasset J., "Stumpfheit”, 31, O.C., VII, p. 164.

9 "Toda mística es un intelectualismo y en la historia aparece siempre en épocas de plétora de ideas (India, Alejandría) o en épocas de grandes novedades científicas que cuajan rapidísimamente con estampido como algunas composiciones químicas -en concepciones cósmicas” (ibid, 36, pp. 164 s.).

10 "Además de significar el problema del individuo, la mística tiene derecho a la vida. El científico suele cometer el error de negar valor y significancia a todo lo que no es ciencia. No: el arte tiene también su lugar junto al de la ciencia. Y la mística es un arte metafísico" (ibid, p.166).

${ }^{11}$ Ortega y Gasset, J., ¿Qué es filosofía?, lección IV, O.C., VIII, p. 287.

12 Hay una referencia a la táctica dramática de los místicos en ¿Qué es filosofía?, O.C, VIII, p. 295.

13 Ibid, p. 288.

14 "Sólo cada cual puede llegar a él y el libro místico se diferencia de un libro científico en que no es una doctrina sobre la realidad trascendental sino el plano de un camino para llegar a esa realidad, el discurso de un método, el itinerario de la mente hacia lo Absoluto. El saber místico es intransferible y, por esencia, silencioso” (ídem). 
Bergson, hayan sido además geniales pensadores, pero la riqueza de su pensamiento contrasta con la miseria de sus averiguaciones extáticas ${ }^{15}$.

El misticismo tiende a explorar la profundidad, mientras que la filosofía, por el contrario, intenta emerger de lo profundo a la superficie. La vocación de la filosofía no es callar sino decir, ser el secreto a voces ${ }^{16}$.

Pero el místico también se ocupa del mundo. Es inútil todo empeño de vivir sin ocuparse de las cosas del mundo. El retirarse de las cosas es un ocuparse con ellas. La contemplación es, en definitiva, un ocuparse con las últimas cosas ${ }^{17}$. En rigor la pura contemplación no existe ${ }^{18}$.

A pesar de sus radicales diferencias, "Oriente y Occidente han solido encontrarse en las cimas de las mentes místicas" 19 .

Ortega señala la gran semejanza entre el enamoramiento y el entusiasmo místico. Cuando el místico habla de la "presencia de Dios" no se trata de una mera frase. Algo semejante sucede al amante con la presencia de la amada ${ }^{20}$. El enamoramiento

\footnotetext{
15 "Sería, pues, un error desdeńar lo que ve el místico porque sólo pueda verlo él. Hay que raer del conocimiento la democracia del saber, según la cual sólo existiría lo que todo el mundo puede conocer. No; hay quien ve más que los demás y estos demás no pueden correctamente hacer otra cosa que aceptar esa superioridad cuando ésta es evidente. Dicho de otra forma: el que no ve tiene que fiarse del que ve. Pero se dirá: ‘cómo podemos certificar que alguien ve, en efecto, lo que no vemos? El mundo está lleno de charlatanes, de vanidosos, de embaucadores, de dementes. El criterio en este caso no me parece de difícil hallazgo: yo creeré que alguien ve más que yo cuando esa visión superior, invisible para mí, le proporciona superioridades visibles para mí. Juzgo por sus efectos. Conste, pues, que no es la inefabilidad ni la imposible transferencia del saber místico lo que hace al misticismo poco estimable -ya veremos cómo existen, en efecto, saberes que por su consistencia misma son incomunicables y alientan inexorablemente prisioneros del silencio. Mi objeción frente al misticismo es que de la visión mística no redunda beneficio alguno intelectual. Por fortuna, algunos místicos han sido antes que místicos geniales pensadores -como Plotino, el maestro Eckehart y el seńor Bergson. En ellos contrasta peculiarmente la riqueza, la fertilidad de pensamiento lógico o expreso, con la miseria de sus averiguaciones extáticas" (ibid, pp. 288 s.).

16 "La filosofía es un enorme apetito de transparencia y una resuelta voluntad de mediodía. Su propósito radical es traer a la superficie, declarar, descubrir lo oculto o velado... Si el misticismo es callar, filosofar es decir, descubrir en la gran desnudez y transparencia de la palabra el ser de las cosas, decir el ser -ontología. Frente al misticismo la filosofía quisiera ser el secreto a voces (ibid, p. 289).

17 "Inclusive cuando el místico se "retira" íntimamente del mundo, se desinteresa del contorno, sigue ocupándose con el mundo en primer lugar, porque en la vida todo es actuar, y el "retirarse" de las cosas es una ocupación con ellas como otra cualquiera que hay que hacer y rehacer constantemente; en segundo lugar, porque se "retira" del mundo para ocuparse de Dios, el cual, vitalmente, es intramundano, pertenece al mundo" (Ortega y Gasset, J., ¿Qué es la vida? Lecciones del curso 1930-1931, O.C., VIII, p. 432).

18 "Lo que el griego y el místico cristiano llamaban vita contemplativa no era tal, en rigor. Para uno como para otro la contemplación significó una efectiva manipulación de cosas, sólo que de las últimas cosas, de las realidades trascendentes: Dios, el universo, el sentido de la vida" (Ortega y Gasset, J., "Los "nuevos" Estados Unidos", O.C., IV, p. 621).

19 Ortega y Gasset, J., "Para un libro no escrito", Espiritu de la letra, O.C., IV, p. 158.

${ }^{20}$ Tras ella hay un fenómeno auténtico. A fuerza de orar, meditar, dirigirse a Dios, llega éste a cobrar ante el místico tal solidez objetiva que le permite no desaparecer nunca de su campo mental. Se halla allí siempre, por lo mismo que la atención no lo suelta. Todo conato de movimiento le hace tropezar con Dios, es decir, recaer en la idea de él. No es, pues, nada peculiar al orden religioso. No hay cosa que no pueda conseguir esa presencia permanente que para el místico goza Dios... También para el enamorado la amada posee una presencia ubicua y constante. El mundo entero está como embebido en ella. En rigor, lo que pasa es que el mundo no existe para
} 
es un encantamiento. Existe una semejanza profunda entre el enamoramiento y el misticismo. Una prueba se encuentra en el hecho de que el místico se exprese mediante palabras e imágenes propias del erotismo. Pero también el enamorado propende al uso de expresiones religiosas. "El proceso místico es como mecanismo psicológico análogo al enamoramiento" ${ }^{21}$.

"El misticismo es también un fenómeno de la atención" 22 . Se trata de prescindir de las cosas y fijar la atención en un solo objeto. "No hay arrobo místico sin previo vacío de la mente" ${ }^{23}$. En este vacío de la mente encuentra el místico a Dios. Pero ni siquiera Dios ha de ser objeto de la mente. Afirma Ortega que "Eckhart razona muy bien la relativa inferioridad de todo estado en que Dios sea aún objeto de la mente" ${ }^{24}$. El grado supremo de la carrera mística no es el pensamiento de Dios, sino "aquél en que el hombre se halle saturado de Dios, hecho esponja de la divinidad. Entonces puede volverse de nuevo al mundo y ocuparse en afanes terrenos, porque ya obrará en rigor como un autómata de Dios" ${ }^{25}$. El místico vive en el mundo terrenal sólo en apariencia; donde verdaderamente está es en el otro donde habita él solo con Dios ${ }^{26}$. El místico, como el amante, están fuera de sí y del mundo: el éxtasis ${ }^{27}$. Existen dos clases de hombres: los que sienten la felicidad como un estar fuera de sí, y los que sólo se sienten en plenitud cuando están sobre sí2 ${ }^{28}$. Por otra parte, Ortega señala un paralelismo entre misticismo e hipnosis y entre hipnotismo y enamoramiento ${ }^{29}$.

En Ortega coexiste un desdén hacia el misticismo con una enérgica defensa o, al menos, intensa comprensión. Comencemos por lo primero, por la censura. La mística resulta ser enemiga de la razón y del clasicismo y oficio de confusión. Los místicos sienten horror hacia las definiciones ${ }^{30}$.

Se refiere irónicamente en 1910 al misticismo a propósito de una crítica a la afirmación del Papa según la cual España ha logrado demostrar que la religión es causa de la felicidad de las naciones ${ }^{31}$.

el amante. La amada lo ha desalojado y sustituido" (Ortega y Gasset, J., "Amor en Stendhal", en Estudios sobre el amor, O.C., V, p.481).

${ }^{21}$ Ibid, p. 485.

22 Ibid, p. 486.

${ }^{23}$ Ibid, p. 487.

${ }^{24}$ Ibid, p. 488.

25 Ídem.

${ }^{26}$ Ibid, p. 489.

${ }^{27}$ Ibid, p.490.

${ }_{28}$ Ídem.

${ }^{29}$ Ibid, pp. 491-495.

30 "Los místicos y los mixtificadores han tenido siempre horror hacia las definiciones porque una definición introducida en un libro místico produce el mismo efecto que el canto del gallo en un aquelarre: todo se desvanece" (Ortega y Gasset, J., "Asamblea para el progreso de las ciencias", O.C., I, pp. 183 s.).

31 “¿Cree el lector que Espańa sea realmente feliz? El Santo Padre dedica casi toda su atención a las realidades místicas, a ese mundo ingrávido y trascendente, poblado de materias sutilísimas: vive una vida sobrehumana, 
De pasada, y acaso sin venir mucho a cuento, a propósito de los avatares de la lengua francesa, afirma con ausencia de todo matiz:

"No creáis a quien os diga que lo que vale más en el hombre es lo inexpresable. Eso es una viejísima mentira de los místicos y los confusionarios enemigos del hombre" 32 .

A propósito de la oratoria, también exhibe en 1911 su desdén hacia el místico.

"El loco, o su hermano menor el místico, verdaderamente sólo se preocupa de hallarse concorde consigo mismo". Y un poco más adelante: "Yo no simpatizo con el loco y el místico" ${ }^{33}$.

En otra ocasión emparenta al místico con el demócrata. Al reivindicar la "gracia animal humana" con todas sus potencias específicas previas a la cultura, se refiere a Napoleón como caso más notorio, "frente a cuya deslumbrante ejemplaridad vital quieren taparse los ojos beatos de una u otra observancia: el místico y el demócrata". ${ }^{34}$

También se refiere a "las filosofías tumultuosas que reinan en las sazones románticas y suelen prolongar algunos descubrimientos de innegable valor en equívocas gesticulaciones místicas" y menciona a Heráclito, Plotino, Paracelso, Schelling, Schopenhauer y Bergson ${ }^{35}$. Y un poco más adelante vuelve a separar la filosofía y la mística ${ }^{36}$.

Reprocha a la mística en general la inclinación a hablar de lo que no se sabe de hecho ni puede saberse de derecho ${ }^{37}$. Y distingue entre el misticismo y la religión, a favor de la segunda ${ }^{38}$.

La conclusión de esta visión negativa está en el título "Defensa del teólogo frente al místico" que contiene un fragmento del curso ¿Qué es filosofía? ${ }^{39}$

También se encuentra en sus textos una valoración favorable del misticismo. Así, en un texto juvenil, de 1904, expresa cuánto hay de español en el misticismo

habita extáticas ciudades, donde con su bastón venerable mantiene el orden de la gracia en la comunión de los santos... No me parece fácil de comprender cómo el país menos culto de Europa puede ser el más religioso. ¿Por ventura la religión es cosa distinta de la cultura?" (Ortega y Gasset, J., "Venerables ironías", O.C., I, p. 355.

32 Ortega y Gasset, J., "Problemas culturales", O.C., II, p. 126.

${ }^{33}$ Ortega y Gasset, J., "Vejamen del orador", O.C., pp.140 s.

${ }^{34}$ Ortega y Gasset, J., El tema de nuestro tiempo, O.C., III, p. 604.

${ }^{35}$ Ortega y Gasset, J., "Tendencias actuales de la filosofía", O.C., VII, p.245.

36 "Es posible, seńores, que la mística sea una forma superior de la cultura. No digo que sí ni que no, por el momento: no quisiera que fueran de combate estas conferencias. Pero esté fuera de duda que frente a la mística la filosofía propiamente tal, la ciencia filosófica no aspira a ser otra cosa que una docta ignorancia" (ídem).

${ }^{37}$ Ortega y Gasset, J., "[Algunos reparos a Jacinto Benavente]", O.C., p. 143.

38 "Donde la religión abre su tienda frente a la de la ciencia, la religión es suplantada por el misticismo, que quiere también ser una contemplación, una visión de las cosas, una teoría. Y el misticismo conforme se adhiere a la religión, se infunde en todas las demás actividades del hombre... Como se ve misticismo es una cosa que han montado los hombres para no trabajar" (ibid, p. 144).

39 Ortega y Gasset, J., O.C., V, pp. 727-731. 
de Maeterlinck, y se refiere a "la melancolía de nuestro misticismo, que es el poso íntimo del alma española” ${ }^{40}$. También son los místicos algo así como la avanzadilla o los vigías de la humanidad, los videntes que llegan los primeros a las tierras prometidas ${ }^{41}$.

También afirma que hoy (1910) sólo los místicos pueden realizar un trato mano a mano con algo que pretenda ser ilimitado y absoluto, los místicos que son "apaches de la divina sustancia, gente que atraca en la soledad de un éxtasis al buen Dios transeúnte" ${ }^{42}$.

Ortega incluye al místico, junto al poeta y al filósofo, entre los hombres de intensa y rica vida interior ${ }^{43}$.

Conviene distinguir entre la mística en sentido clásico y general y lo místico considerado como lo trascendente, lo que no pertenece al mundo, lo que vincula al hombre con lo Absoluto. En este segundo sentido, la posición de Ortega parece mucho más inequívoca que en el primero.

Una de las principales enseñanzas de Ortega es que sólo desde nuestra propia circunstancia personal es posible tener acceso a la verdad. La filosofía, como la Universidad a la que está íntimamente vinculada, sólo es posible a partir de la existencia de un modo de vida, de un ideal de vida teórica en busca de la verdad, que presupone la existencia de una comunidad espiritual.

Tanto en el sistema de Ortega como, quizá sobre todo, en su actitud personal y en la tradición filosófica en la que se inserta se encuentra una de las posibilidades más fértiles para restaurar una comunidad intelectual que permita la fusión de lo temporal y lo eterno, que es acaso la misión filosófica de nuestro tiempo.

Toda la obra filosófica de Ortega persigue una reforma radical de la filosofía que consiste en la superación del idealismo y, con ella, en la crítica de la modernidad. Ortega indica un rumbo por donde puede arribarse a la superación del racionalismo moderno sin recaer en el irracionalismo y el relativismo. El filósofo madrileńo reivindica la filosofía como teoría del universo, como búsqueda de lo absoluto, la afirmación de la verdad frente al escepticismo y el relativismo y la consideración de la vida personal individual como realidad radical. El raciovitalismo y el perspectivismo orteguianos no son una forma de subjetivismo. La superación del idealismo

\footnotetext{
${ }^{40}$ Ortega y Gasset, J., "El poeta del misterio", O.C., I, p. 32.

41 "Los místicos han estado durante todos los tiempos de pie en la frontera de lo desconocido: han sido los vigías de la humanidad que, izados en el ensueño o en el éxtasis, dan las voces de alerta al divisar las brumas rosadas que anuncian costa. Los sabios, con toda su impedimenta y sus andares de camellos cansados, llegan a las tierras prometidas siglos más tarde que los videntes. Y esto es una burla amarga del hado, porque sabio podrá serlo quien quiera, y vidente sólo el que lo sea desde la eternidad" (ídem).

42 Ortega y Gasset, J., "La teología de Renan”, O.C., I, p. 333.

43 Ortega y Gasset, J., "Vitalidad, alma, espíritu”, El Espectador, V, O.C., II, p. 573.
} 
entraña la reforma de la idea moderna de la razón, el descubrimiento de la razón vital, que establece una nueva relación entre la cultura y la vida.

La teoría de la perspectiva es una teoría de la verdad y de la realidad que no niega la existencia de verdades objetivas e incluso eternas, sino que reconoce el carácter circunstancial, inherente a la vida humana, de la búsqueda y descubrimiento de las verdades.

No hay que confundir "realidad radical" con "realidad absoluta" o "ser fundamental". El mundo no se explica a sí mismo y esto deja abierto el camino a la cuestión de Dios, del Ser fundamental. El mundo es fragmento.

"El ser fundamental, por su esencia misma, no es un dato, no es nunca un presente para el conocimiento, es justo lo que falta a todo presente" ${ }^{44}$.

La filosofía es teoría del universo, es decir, sistema de conceptos sobre todo cuanto hay. Sus dos características fundamentales son la "autonomía" y la "pantonomía". Según la primera, no puede dar nada por supuesto. La segunda consiste en la voluntad de referirse y dar cuenta de todo cuanto hay. La consecuencia principal del principio de autonomía es que el filósofo debe buscar una primera verdad tan evidente que no pueda ponerse en duda y sobre la que edificar el sistema entero de la filosofía. A esta realidad que no puede ponerse en duda por su evidencia inmediata llama Ortega "realidad radical". No se trata de la realidad absoluta o fundamental, sino tal vez de la más modesta de todas, pero que no puede ponerse en duda por su evidencia, y de la que la filosofía tiene necesariamente que partir. Y se puede calificar como radical precisamente porque todas las demás se dan o radican en ella. Esta realidad radical es, para Ortega, mi vida, la de cada cual.

La realidad radical debe ser distinguida del ser fundamental. La realidad radical es la más evidente pero no fundamenta a las demás realidades, sino que ella misma debe ser fundamentada, ya que es, en sí misma, menesterosa de sentido. La vida personal no es para Ortega la realidad absoluta que fundamente a todas las demás. Difícilmente podría además serlo, ya que existe una pluralidad de vidas humanas, y sería absurdo predicar de cada una de ellas el carácter absoluto. Además, cada vida individual no es necesaria sino contingente. El primer problema de la filosofía, no el más importante, consiste en determinar cuál es la realidad más indudable, más segura ${ }^{45}$. Se trata sólo del primer problema, del preliminar, pero deja intocado el problema acerca de si hay otras realidades más importantes o fundamentales ${ }^{46}$.

\footnotetext{
${ }_{44}$ Ídem.

45 "El problema primero de la filosofía no es averiguar qué realidad es la más importante, sino qué realidad del Universo es la más indudable, la más segura -aunque sea, por caso, la menos importante, la más humilde e insignificante. En suma, que el problema primero filosófico consiste en determinar qué nos es dado del Universo -el problema de los datos radicales" (ibid., p. 360).

46 "Si creemos que ese dato [el previo] es nuestra vida, que del Universo a cada cual le es dado sólo su vivir, no nos permitimos la más ligera opinión aún sobre si, además de esto que nos es dado, no hay, bien que no dadas, otras
} 
No sólo no agota el ámbito de lo real, ni mucho menos el de la realidad fundamental; ni siquiera agota el ámbito de la filosofía, que es, ante todo, el del sentido del ser, el del ser fundamental y fundamentante. Después, el sistema de la filosofía se abrirá a esas otras realidades más importantes y fundamentales, pero menos indubitables en el orden de la evidencia. Es lo mismo que sucede en las obras de Descartes y Husserl.

El problema de los datos previos del Universo, la búsqueda de una primera certeza indubitable, es el primer problema de la filosofía, pero no el último ni el fundamental. Lo más seguro y evidente no tiene por ello que ser lo fundamental. El mundo es fragmento, algo incompleto que necesita ser completado por el ser fundamental ${ }^{47}$.

La materia no se basta sí misma, ni se da a sí misma el ser. La materia ha tenido que ser puesta en la existencia por algún otro poder ${ }^{48}$.

Lo que vemos es sólo fragmento que postula la necesidad de lo "compresente", del mundo ${ }^{49}$. Pero, a su vez, el mundo como un todo es asimismo fragmentario y postula la "compresencia" de lo que no es el mundo. El mundo tampoco se explica a sí mismo ${ }^{50}$.

Si el mundo es fragmento, no encuentra en sí el fundamento de su propio ser, no se basta a sí mismo.

Como explica Julián Marías: "El mundo no se explica tampoco a sí mismo. Es sólo un problema, un objeto insuficiente y fragmentario, fundado en algo que no es él, que no es lo dado. Ese algo tiene una misión fundamentadora, es el ser fundamental' ${ }^{51}$. Esta insuficiencia del mundo, obliga a la filosofía a postular la necesidad de la existencia del ser fundamental.

realidades mucho más importantes. El problema de lo dado o indubitable no es la filosofía, sino sólo su dintel, su capítulo preliminar" (ídem).

47 “Todo lo que es y está ahí, cuanto nos es dado, presente, patente es por su esencia mero trozo, pedazo, fragmento, muńón. Y no podemos verlo sin prever y echar de menos la porción que falta. En todo ser dado, en todo dato del mundo encontramos su esencial línea de fractura, su carácter de parte y sólo parte -vemos la herida de su mutilación ontológica, nos grita su dolor de amputado, su nostalgia del trozo que le falta para ser completo, su divino descontento" (ibid., p. 279).

48 "Si la materia una vez que existe, que está ahí se basta a sí misma, no ha podido darse el ser, no ha podido venir al ser por su propia capacidad. No se puede pensar la materia sin verla como algo que ha sido puesto en la existencia por algún otro poder, como no se puede ver la flecha en el aire sin que busquemos la mano que la ha lanzado" (ibid, p. 280).

49 "Lo que en cada caso vemos es sólo el promontorio visible que hacia nosotros adelanta el resto latente de mundo. Y así podemos elevar a ley general esta observación y decir: presente algo, está compresente el mundo" (ídem).

50 "El mundo entero, el conjunto de lo que nos es dado y que por sernos dado podemos llamarlo "nuestro mundo", será también un fragmento enorme, colosal, pero fragmentario y nada más. El mundo no se explica tampoco a sí mismo; al contrario, cuando nos encontramos teóricamente ante él, nos es dado sólo... un problema” (ibid., p. 281).

51 Marías, J., Ortega 2. Las trayectorias, Madrid, Alianza, 1983, p. 283. 
"Parejamente, el mundo que hallamos es, pero a la vez, no se basta a sí mismo, no sustenta su propio ser, grita lo que le falta, proclama su no-ser y nos obliga a filosofar, buscar al mundo su integridad, completarlo en Universo y a la parte construirle un todo donde se aloje y descanse. Es el mundo un objeto insuficiente y fragmentario, un objeto fundado en algo que no es él, que no es lo dado. Ese algo tiene, pues, una misión sensu stricto fundamentadora, es el ser fundamental. Como Kant decía: "Cuando lo condicional nos es dado, lo incondicional nos es planteado como problema”. He aquí el decisivo problema filosófico y la necesidad mental que hacia él nos dispara" ${ }^{52}$.

Ortega afirma que "la filosofía parte a la descubierta de otro mundo" 53 , que, necesariamente, no es éste.

"Todas las filosofías nos presentan el mundo habitual dividido en dos mundos, un mundo patente y un trasmundo o supermundo que late bajo aquel y en poner de manifiesto el cual estriba la culminación de la tarea filosófica" ${ }^{54}$.

El ser fundamental no nos es presente, no es un dato, no pertenece al mundo, ni cabe buscarlo en él.

"El ser fundamental, por su esencia misma, no es un dato, no es nunca un presente para el conocimiento, es justo lo que falta a todo presente. ¿Cómo sabemos de él? Curiosa aventura la de ese extraño ser" ${ }^{\prime 5}$.

$\mathrm{Ni}$ el Ser fundamental es una cosa del mundo, que no hayamos encontrado en él hasta ahora pero que podamos algún día descubrir, ni puede ser considerado como homogéneo al ser intramundano.

Ortega distingue entre Dios, que es el problema de la teología, y el Ser fundamental, tema exclusivo de la filosofía. Eso no impide que uno y otro problema se relacionen, en el sentido de que Dios es, para la religión, el ser fundamental que postula la filosofía y que, al parecer, para Ortega, no puede conocer. Dios y el Ser fundamental son, pues, la misma realidad. La religión habla, según nuestro autor, del primero; la filosofía, del segundo. En cualquier caso, queda claro el radical error filosófico que entraña el materialismo, al que Ortega califica como "pseudofilosofía subversiva".

La filosofía de Ortega entraña una apertura a la trascendencia, una afirmación de su existencia y necesidad. Incluso una apertura a la idea de Dios. Después de afirmar su preferencia del teólogo frente al místico, afirma: "Yo creo que el alma

\footnotetext{
52 Ortega y Gasset, J., ¿Qué es filosofía?, O.C., VIII, p. 281.

53 Ortega y Gasset, J., "La filosofía parte a la descubierta de otro mundo", O.C., IX, p. 715-720.

54 Ibid, p.715.

55 Ortega y Gasset, J., ¿Qué es filosofía?, op. cit., p. 281.
} 
europea se halla próxima a una nueva experiencia de Dios, a nuevas averiguaciones sobre esa realidad, la más importante de todas" ${ }^{56}$.

No sólo cabe hablar de Dios; es que se trata de la realidad más importante de todas.

Y no se limitan estas ideas a la etapa en la que pronuncia estas lecciones, sino que pueden encontrase otras semejantes en épocas anteriores en las que parece mucho más limitada su sensibilidad religiosa. Cabe mencionar, por ejemplo, sus consideraciones sobre el silencio y la vida retirada en "Las ermitas de Córdoba" (1904). También su rechazo de la concepción chabacana de la religión que la considera como un prejuicio del que haya que liberarse.

De 1926 es el artículo "Dios a la vista". En él defiende la tesis de que el tiempo presente pertenece a aquellos en los que Dios, lejos de casi desaparecer en el horizonte, se aproxima a las costas humanas y se avista desde ellas. En el paisaje del agnosticismo, faltan precisamente las cosas últimas y las primeras, es decir, las decisivas. Es un paisaje de miope y mutilado, en el que se elimina todo lo primario y decisivo, y se renuncia a todo lo fundamental ${ }^{57}$.

Y termina el ensayo con estas palabras:

"Frente a estas dos preferencias antagónicas [el agnosticismo y el gnosticismo] e igualmente exclusivas cabe que el atender se fije en una línea intermedia, precisamente la que dibuja la frontera entre uno y otro mundo. Esa línea en que "este mundo" termina, le pertenece, y es, por tanto, de carácter "positivo". Mas a la vez, en esa línea comienza el ultramundo, y es, en consecuencia, trascendente. Todas las ciencias particulares, por necesidad de su interna economía, se ven hoy apretadas contra esa línea de sus propios problemas últimos, que son, al mismo tiempo, los primeros de la gran ciencia de Dios" 58 .

Las repercusiones de estas ideas para la fundamentación de la realidad de la trascendencia resultan patentes.

Hay, pues, una realidad trascendente al mundo y a la vida. Como afirma J. H. Walgrave, O. P., "tiene que haber, pues, una realidad que es trascendente respecto

\footnotetext{
${ }^{56}$ Ibid., p.290.

57 "La consecuencia de ello es que el paisaje agnóstico no tiene últimos términos. Todo en él es primer plano, con lo cual falta a la ley elemental de la perspectiva. Es un paisaje de miope y un panorama mutilado. Se elimina todo lo primario y decisivo. La atención se fija exclusivamente en lo secundario y flotante.

Se renuncia con laudables pretextos de cordura a descubrir el secreto de las últimas cosas, de las cosas "fundamentales", y se mantiene la mirada fija exclusivamente en "este mundo". Porque "este mundo" es lo que queda del Universo cuando le hemos extirpado todo lo fundamental; por tanto, un mundo sin fundamento, sin asiento, sin cimiento, islote que flota a la deriva sobre un misterioso elemento" ("Dios a la vista", El Espectador, VI, O.C., II, pp. 606 s.).

${ }^{58}$ Ibid, p. 607.
} 
de la vida y que se afirma frente a la conciencia como existiendo independientemente" 59 .

Walgrave sostiene que, según Ortega, nuestras ideas pueden encontrarse de un doble modo en nuestra vida: como meras ideas o como signos de una presencia inmediata. En el primer caso son invenciones; en el segundo, revelaciones. Y cita a Ortega en Historia como sistema: entonces "la idea desaparece como tal idea y se convierte en un puro modo de patética presencia que una realidad absoluta elige. Entonces la idea no nos parece ni idea ni nuestra. Lo trascendente se nos descubre por sí mismo, nos invade e inunda -y esto es la revelación-“"

Walgrave concluye que Ortega nunca rechazó la religión como una mentira ${ }^{61}$ y que su humanismo le orientó hacia una dirección religiosa ${ }^{62}$ y le produjo una tendencia hacia la realidad absoluta ${ }^{63}$.

Antonio Regalado García ha defendido la existencia de una visión gnóstica en la filosofía de Ortega. Según él, la experiencia cristiana de la existencia que concibe este mundo como un valle de lágrimas es mucho más profunda que la griega ${ }^{64}$.

Antonio Regalado afirma que Ortega quedó fascinado por la mitología cristia$\mathrm{na}^{65}$, pero que, en definitiva, su visión de la realidad es inmanentista y, por tanto, no cristiana ${ }^{66}$. Esta visión gnóstica de Ortega me parece equivocada pero, al menos, reconoce el valor soteriológico de su filosofía que desemboca en una teodicea ${ }^{67}$.

Por lo demás, Ortega defiende la compatibilidad de su filosofía con la fe cristiana.

"Ni ésta ni ninguna de las demás cosas que yo diga en este curso puede causar erosión alguna en la fe cristiana de nadie. Esto no es peculiar a mi pensamiento filo-

59 Walgrave, J. H., O. P., La filosofia de Ortega y Gasset, Madrid, Revista de Occidente, 1965, p. 250.

${ }^{60}$ Ibid, p. 255.

${ }^{61}$ A pesar de que Ortega "ha hablado pocas veces y siempre sólo de paso sobre el problema en torno a Dios, nunca ha rechazado la religión como una mentira. Nunca ha dicho que la idea de Dios sea tan sólo una idea y que esa idea no pueda iluminarse con una chispa que salte del misterio de la realidad" (ibid, pp. 307 s.).

${ }^{62}$ "También el humanismo de Ortega ha de orientarle desde el hombre hacia una dirección religiosa" (ibid, p. 311).

${ }^{63}$ Ibid, p. 318.

${ }^{64}$ Regalado García, A., El laberinto de la razón: Ortega y Heidegger, Madrid, Alianza, 1990, p.287. "No obstante, Ortega describió la condición humana con una retórica que coincidía con el discurso gnóstico-cristiano, similitud que hubiera aceptado sólo como punto de partida para trascenderla. Alérgico a todo lo sobrenatural, el filósofo se detiene en una definición del hombre como ser "extranatural" y de la vida humana como "extrańa condición" que hace del hombre el "único ser infeliz", precisamente porque "necesita ser lo que no es"” (ibid, p. 290).

65 "Al acercarse Ortega a las verdades del cristianismo, a la experiencia vital e histórica de la fe como vivencia y no a su contenido específico, quedó fascinado por la mitología cristiana" (ibid, p. 291).

66 "Ortega ha restado la verdad escatológica trasmundana al cristianismo y se ha quedado con la verdad inmanente de la vivencia de la fe, es decir ha fundado su ontología valientemente en el vacío, en una experiencia nihilista de una realidad desprovista de Dios y del Ser, constituida sólo por el afán de ser” (ibid, p. 292).

${ }^{67}$ Ibid, p. 304. 
sófico, sino que es oportuno afirmar que desde hace cincuenta años ninguna filosofía, al menos entre las notorias y vigentes, ha entrado en colisión con la fe religiosa. Y esto no por voluntad deliberada de evitarlo, sino porque la filosofía ha acabado por ver con claridad que habla de cosas distintas de las que habla la teología" ${ }^{68}$.

No obstante, Ortega incluye a los cristianos entre los supervivientes del pasado ${ }^{69}$.

El mundo no es todo cuanto hay; es fragmento. El mundo no se explica a sí mismo, sino que es radicalmente menesteroso. La perspectiva de la ciencia es incompleta. Es la necesidad de encontrar un fundamento del mundo lo que nos obliga a filosofar. El ser fundamental es la realidad absoluta que dota de sentido y fundamento al mundo. El ser fundamental no es una cosa del mundo, sino que existe una radical heterogeneidad entre él y el mundo. El ser fundamental no pertenece al mundo; es trascendente. La realidad radical, la primera en el orden de la evidencia, aquella de cuya existencia no se puede dudar, es la vida personal de cada cual. Pero la realidad radical no es el Ser fundamental, que dota de sentido y fundamento al mundo y a la vida humana. El Ser fundamental es Dios (o, al menos, lo que la filosofía llama ser fundamental es lo mismo que aquello a lo que la teología y la religión llaman Dios). La filosofía de Ortega entraña una crítica radical al monismo, al materialismo y al sensualismo. Defiende, por el contrario, el dualismo (mundo y trasmundo), la afirmación de la realidad espiritual de la persona y el raciovitalismo, frente al racionalismo y al vitalismo. Hay que rechazar toda interpretación inmanentista de la filosofía de Ortega. No están ausentes las "ultimidades" en su filosofía. No podemos renunciar a la adopción de posiciones ante los temas últimos. No cabe filosofía auténtica que no se plantee el problema del ser fundamental, ni que no lo sitúe más allá del mundo y de la vida.

En ningún sentido puede decirse que Ortega haya sido un ateo ${ }^{70}$. Esto significa que, ante la polémica sobre la posibilidad de un orteguismo católico y la compatibilidad entre la filosofía de Ortega y la religión cristiana, mi posición es clara: no hay nada en la filosofía de Ortega que sea incompatible con el catolicismo, y, por tanto, es posible, y así ha sucedido en la realidad, un orteguismo católico o un catolicismo orteguiano $^{71}$.

\footnotetext{
${ }^{68}$ Ortega y Gasset, J., “Teología y filosofía”, La razón histórica (Lisboa, 1944), Obras Completas, IX, p. 696.

${ }^{69}$ Ortega y Gasset, J., La rebelión de las masas, O. C., IV, p. 496.

70 "No se puede decir que Ortega haya sido un ateo. Cuando en su lecho de enfermo alguien le habló de Dios, él declaró que había contado siempre con él. Como hombre, no estuvo, pues, solo; pero filosóficamente este Dios tan lejano no le permitía aclarar más" (Gaete, A., El sistema maduro de Ortega, Buenos Aires, Compañía General Fabril Editora, 1962, p. 231).

71 Sobre esta polémica pueden verse, entre otros, los siguientes textos: Ramírez, S., La filosofía de Ortega y Gasset, Barcelona, Herder, 1958; Laín Entralgo, P., "Los católicos y Ortega”, Cuadernos Hispanoamericanos, núm. 101, Madrid, 1958; Marías, J, El lugar del peligro. Una cuestión disputada en torno a Ortega, Madrid, Taurus, 1958; Garagorri, P., Relecciones y disputaciones orteguianas, Madrid, Taurus, 1965, pp. 79-89 y 97-99; Abellán, J. L.,
} 
Parece claro que mi vida es la realidad radical, pero no la más importante de todas, la realidad fundamental. El pensamiento filosófico no puede contentarse "definitivamente con ninguna posición que no exprese valores universales, en suma, que no aspire al Universo" 72 . Al oponerse tanto al anticristianismo como al antimodernismo, ¿acaso está propugnando Ortega un "cristianismo moderno", un "misticismo moderno"? Acaso el "tema de nuestro tiempo" consista en reconciliar la razón y lo místico. Como afirma Miguel García-Baró, "en definitiva, son imposibles la vivencia del cristianismo y la mostración de su relevancia si no van de la mano de una búsqueda absolutamente radical de la verdad" ${ }^{\text {"73 }}$. La filosofía de Ortega no cierra el camino a la experiencia religiosa y a la experiencia mística. Por el contrario, las fundamenta.

Ortega y Gasset y los orígenes de la transición democrática, Madrid, Espasa, 2000, pp. 228-243; Sánchez Villaseñor, J. L., SJ, Pensamiento y trayectoria de José Ortega y Gasset, México, Ius, 1943; Morón Arroyo, C., El sistema de Ortega y Gasset, Madrid, Alcalá, 1968, pp. 417-438; Martín Puerta, A., Ortega y Unamuno en la España de Franco. El debate intelectual durante los años cuarenta y cincuenta, Madrid, Encuentro, 2009; y Maestre, A., Ortega y Gasset. El gran maestro, Córdoba, Almuzara, 2019, pp. 151-199.

72 Ortega y Gasset, J., ¿Qué es filosofía?, op. cit, p. 296.

73 García-Baró, M., De estética y mistica, Salamanca, Sígueme, 2007, p. 80. 


\section{ReFERENCIAS Bibliográficas}

Abellán, J. L., Ortega y Gasset y los origenes de la transición democrática, Madrid, Espasa, 2000.

Gaeta, A., El sistema maduro de Ortega, Buenos Aires, Compañía General Fabril Editora, 1962.

Garagorri, P., Relaciones y disputaciones orteguianas, Madrid, Taurus, 1965.

García-Baró, M., De estética y mistica, Salamanca, Sígueme, 2007, p. 80.

Jaeger, W., The theology of the Early Greek Philosophers, Oxford University Preee, 1947.

James, W., Las variedades de la experiencia religiosa, traducción de F. J. Ivars, Barcelona, Península, 1986.

Laín Entralgo, P., "Los católicos y Ortega", Cuadernos Hispanoamericanos, 101, Madrid, 1958.

Maestre, A., Ortega y Gasset. El gran maestro, Córdoba, Almuzara, 2019.

Marías, J., El lugar del peligro. Una cuestión disputada en torno a Ortega y Gasset, Madrid, Taurus, 1958.

Marías, J. Ortega 2. Las trayectorias, Madrid, Alianza, 1983.

Martín Puerta, A., Ortega y Unamuno en la España de Franco. El debate intelectual durante los años cuarenta y cincuenta, Madrid, Encuentro, 2009.

Morón Arroyo, C., El sistema de Ortega y Gasset, Madrid, Alcalá, 1968.

Ortega y Gasset, Obras Completas, Madrid, Taurus, 2006.

Ramírez, S., La filosofía de Ortega y Gasset, Barcelona, Herder, 1958.

Regalado García, A., El laberinto de la razón: Ortega y Heidegger, Madrid, Alianza, 1990.

Sánchez Villaseñor, J., S.J., Pensamiento y trayectoria de José Ortega y Gasset, México, Ius, 1943.

Walgrave, J. H., O.P., La filosofia de Ortega y Gasset, Madrid, Revista de Occidente, 1965.

Wittgenstein, L., Tractatus logico-philosophicus, traducción de Muñoz, J., y Reguera, I., Madrid, Alianza, 1973.

DOI: https://doi.org/110.15366/bp.2020.24.001

Bajo Palabra. II Época. № 24. Pgs: 21-36 